\title{
Substantial Value of Cardiac Computed Tomography for the Evaluation of Patients with Suspected Prosthetic Valve Dysfunction
}

\author{
Macit Kalcik ${ }^{a}$ Ahmet Güner ${ }^{b}$ Sabahattin Gündüz ${ }^{c} \quad$ Mehmet Özkanc, d $^{c}$ \\ a Department of Cardiology, Faculty of Medicine, Hitit University, Corum, Turkey; ${ }^{b}$ Department of Cardiology, \\ Mehmet Akif Ersoy Thoracic and Cardiovascular Surgery Training and Research Hospital, Istanbul, Turkey; \\ 'Department of Cardiology, Kosuyolu Kartal Heart Training and Research Hospital, Istanbul, Turkey; ${ }^{\mathrm{d}}$ Division of \\ Health Sciences, Ardahan University, Ardahan, Turkey
}

Dear Editor,

We recently read with great interest the article by $\mathrm{Hsu}$ et al. [1] entitled "Cine-Computed Tomography for the Evaluation of Prosthetic Heart Valve Function". We appreciate the contribution made by these authors in this report on the beneficial use of cine-computed tomography $(\mathrm{CT})$ in the evaluation of patients with suspected prosthetic aortic valve dysfunction. Furthermore, we would like to contribute to their report by drawing attention to the role of cardiac CT for the differentiation of periprosthetic masses as a complementary diagnostic tool to transesophageal echocardiography (TEE) in the evaluation of prosthetic heart valves (PHV).

Several noninvasive imaging modalities are available for the assessment of PHV function [2]. Transthoracic echocardiography is usually the first imaging modality to evaluate suspected PHV dysfunction, but usually offers inadequate images for making differential diagnosis of the thrombus, pannus, and vegetation, due to the acoustic shadowing and low resolution caused by prosthetic material. Furthermore, as emphasized by the authors, increased transvalvular flow velocities and pressure gradients measured by Doppler echocardiography may be observed due to increased pressure recovery or patient-

karger@karger.com

(c) 2020 S. Karger AG, Basel

www.karger.com/crd

Karger! prosthesis mismatch in the absence of valvular obstruction. Thus, an abnormality detected on Doppler echocardiography should be further investigated by TEE or cardiac CT which can be useful for evaluating the etiology (i.e., thrombus vs. pannus) of the valvular obstruction. Real-time 3-dimensional (RT-3D) TEE, in particular, provides better visualization of the atrial and ventricular sides of mitral prostheses, improves the understanding of the relation between cardiac structures, and helps in discriminating the pannus from the thrombus $[3,4]$. However, RT-3D TEE has limited ability in the evaluation of aortic PHV due to the distance between the esophagus and the aortic valve. Cinefluoroscopy is a noninvasive, readily available method for detecting PHV dysfunction, especially in patients with bileaflet prosthetic valves, and it can play a complementary diagnostic role in evaluating the disk mobility of the prostheses [5].

Cardiac CT can complement TEE and become an emerging diagnostic tool in the evaluation of mechanical prosthetic valves [6]. Attenuation values of the abnormal masses adjacent to the prosthetic valves may provide quantitative data for the differentiation of pannus and thrombus formation. Based on the histopathologic differences between the pannus and thrombus, X-ray attenuation of 
the pannus may be markedly higher than that of the thrombus. A few previous studies suggested that the mean CT attenuation of the periprosthetic mass as a quantitative imaging feature may be helpful for discerning the pannus [7, 8]. We previously reported a quantitative approach to distinguish the pannus and thrombus by means of cardiac CT. Periprosthetic masses with Hounsfield units (HU) $\geq 145$ were associated with the presence of pannus formation with high sensitivity and specificity whereas a lower value was associated with thrombus formation. Furthermore, masses with $\mathrm{HU}<90$ were almost always completely lysable with thrombolytic therapy [9]. Furthermore, the cineCT technique may be very helpful for the evaluation of suspected prosthetic valve dysfunction in the clinical set- ting. Electrocardiography-gated cine-CT allows the direct observation of valve leaflet mobility throughout the cardiac cycle by means of 4 -dimensional (i.e., including time) image reconstruction. The functional and morphological assessment of PHV by cine-CT has improved with developments in image resolution over time [10].

In conclusion, cine-CT is a powerful complementary tool that can provide a clear motion-picture of normal valve function in patients with suspected prosthetic valve dysfunction. Despite the limitations of streak artifacts and volume averaging, cardiac CT has an incremental value in identifying and characterizing periprosthetic masses and can guide the treatment of patients with prosthetic valve dysfunction.

\section{References}

1 Hsu C, Bourganos K, Zafar MA, Huber S, Buntin J, Ziganshin BA, et al. Cine-Computed Tomography for the Evaluation of Prosthetic Heart Valve Function. Cardiology. 2020; 145(7):439-45.

2 Gündüz S, Kalçık M, Gürsoy MO, Güner A, Özkan M. Diagnosis, treatment \& management of prosthetic valve thrombosis: the key considerations. Expert Rev Med Devices. 2020 Mar;17(3):209-21.

3 Özkan M, Gürsoy OM, Astarcıoğlu MA, Gündüz S, Cakal B, Karakoyun S, et al. Realtime three-dimensional transesophageal echocardiography in the assessment of mechanical prosthetic mitral valve ring thrombosis. Am J Cardiol. 2013 Oct;112(7):977-83.

4 Özkan M, Gündüz S, Yildiz M, Duran NE. Diagnosis of the prosthetic heart valve pannus formation with real-time three-dimensional transoesophageal echocardiography. Eur J Echocardiogr. 2010 May;11(4):E17.

5 Gürsoy MO, Kalçık M, Yesin M, Karakoyun S, Bayam E, Gündüz S, et al. A global perspective on mechanical prosthetic heart valve thrombosis: diagnostic and therapeutic challenges. Anatol J Cardiol. 2016 Dec;16(12): 980-9.

6 Nam K, Suh YJ, Han K, Park SJ, Kim YJ, Choi BW. Value of Computed Tomography Radiomic Features for Differentiation of Periprosthetic Mass in Patients with Suspected Prosthetic Valve Obstruction. Circ Cardiovasc Imaging. 2019 Nov; 12(11):e009496.

7 Teshima H, Aoyagi S, Ueda T, Takagi K, Shojima T, Tanaka H. Evaluation of advancing the standard valve dysfunction by multidetector-row CT. J Artif Organs. 2014 Jun; $17(2): 162-8$
8 Ueda T, Teshima H, Fukunaga S, Aoyagi S, Tanaka $\mathrm{H}$. Evaluation of prosthetic valve obstruction on electrocardiographically gated multidetector-row computed tomography-identification of subprosthetic pannus in the aortic position. Circ J. 2013;77(2): 418-23.

9 Gündüz S, Özkan M, Kalçik M, Gürsoy OM, Astarcioğlu MA, Karakoyun S, et al. Sixty-four-section cardiac computed tomography in mechanical prosthetic heart valve dysfunction: thrombus or pannus. Circ Cardiovasc Imaging. 2015 Dec;8(12): e003246.

10 Numata S, Tsutsumi Y, Monta O, Yamazaki $\mathrm{S}$, Seo H, Yoshida S, et al. Mechanical valve evaluation with four-dimensional computed tomography. J Heart Valve Dis. 2013 Nov; 22(6):837-42.
Substantial Value of Cardiac Computed Tomography for the Evaluation of Patients with Suspected Prosthetic Valve Dysfunction 